\title{
Prevalence of Shiga Toxin-Producing Escherichia coli and Associated Virulence Genes in Feces of Commercial Feedlot Cattle
}

\author{
Natalia Cernicchiaro, Charley A. Cull, Zachary D. Paddock, ${ }^{\star}$ Xiaorong Shi, \\ Jianfa Bai, Tiruvoor G. Nagaraja, and David G. Renter
}

\begin{abstract}
The objective of this study was to determine the prevalence of Shiga toxin-producing Escherichia coli (STEC) serogroups and associated virulence genes in feces of commercial feedlot cattle. During March to May 2011, fecal samples were collected from individual cattle $(n=960)$ in 10 cohorts (cattle subpopulations within a feedlot) comprising 17,148 total steers that originated from 48 backgrounding operations in six U.S. states. Fecal samples were enriched in E. coli broth and subjected to two detection protocols: (1) an 11-gene multiplex polymerase chain reaction (PCR) that identifies seven O serogroups (O26, O45, O103, O111, O121, O145, and O157) and four virulence genes (stx1, st $x 2$, eae, and $e h x A$ ) applied to extracted total DNA ("direct PCR"); and (2) cultural procedures that involve immunomagnetic separation (IMS) with O26, O103, and O111 beads, plating on a nondifferential MacConkey agar, followed by the multiplex PCR of pooled colonies ("culture-based method"). Generalized linear mixed models were used to adjust prevalence estimates for clustering. Based on direct PCR detection, O157 (49.9\%) was the most prevalent O serogroup followed by O26 (20.3\%), O103 (11.8\%), O121 $(10.7 \%), \mathrm{O} 45(10.4 \%), \mathrm{O} 145(2.8 \%)$, and $\mathrm{O} 111(0.8 \%)$. Cumulative adjusted prevalence estimates were 22.3, 24.6, and $0.01 \%$ for $\mathrm{O} 26, \mathrm{O} 103$, and $\mathrm{O} 111$ serogroups, respectively, based on culture-based methods. However, prevalence varied significantly by cohort ( $p$-values $<0.05$ ) for O26, O121, and O157 based on direct PCR, and for O26, O103, and O111 serogroups based on culture-based methods. Results of this study indicate that all seven STEC serogroups were identified in feedlot cattle feces, with O157, O26, and O103 being the most prevalent serogroups. A substantial proportion of serogroup-positive samples did not harbor Shiga toxin genes; thus, additional elucidation of the potential human health risk is required. Further evaluation of diagnostic methods for non-O157 STEC is needed given their impact on prevalence estimation.
\end{abstract}

\section{Introduction}

S TUdies OF SHIga toxin-Producing Escherichia coli (STEC) in food production systems have focused primarily on serotype O157:H7, despite the fact that human cases of non-O157 STEC have exceeded O157 STEC cases in the United States and Europe (Brooks et al., 2005). The Center for Disease Control and Prevention reported that six non-O157 STEC O groups (O26, O45, O103, O111, O121, and O145) are responsible for over $70 \%$ of non-O157 STEC-associated illnesses in the United States (Brooks et al., 2005; Scallan et al., 2011). Although commodities other than beef (e.g., fruits and nuts, leafy vegetables) have been implicated in non-O157 outbreaks of human illness (Painter et al., 2013), ruminants, including cattle, are considered a major reservoir of non-O157
STEC (Bettelheim, 2000). Most recent studies of beef production systems reporting prevalence of non-O157 STEC serogroups are based on ground beef or carcass samples (Bosilevac et al., 2007; Bosilevac and Koohmaraie, 2011; Fratamico et al., 2011; Hofer et al., 2012). Few studies have reported prevalence in cattle, with wide-ranging estimates from 4.6 to $55.9 \%$ in cattle feces (Jenkins et al., 2003; Renter et al., 2005; Hussein, 2007; Renter et al., 2007).

A U.S. Department of Agriculture Food Safety and Inspection Service (USDA-FSIS) risk profile for non-O157 STEC indicated that there are no data on the prevalence of non-O157 STEC in cattle or cattle carcasses and that these data are needed for quantitative assessments (Pihkala et al., 2012). Furthermore, given the increasing recognition of the clinical relevance and role of non-O157 STEC as foodborne pathogens 
in North America, there is a clear need to gather pre- and periharvest data on the prevalence and distribution of STEC serogroup and virulence factors in beef and cattle production systems. Therefore, the objectives of this study were (1) to determine the point prevalence of STEC serogroups and associated major virulence genes in feces of commercial feedlot cattle, and (2) to determine the agreement between two detection protocols (direct polymerase chain reaction [PCR] and culturebased methods) used to estimate prevalence in cattle feces.

\section{Materials and Methods}

\section{Study population and sampling}

Details on the study population and sampling procedures have been described elsewhere (Cull et al., 2012). Briefly, samples were collected from a commercial feedlot operation in central United States between March and May 2011. Feedlot eligibility criteria were determined based on requirements for a preharvest intervention study (Cull et al., 2012). A total of 17,148 cattle from this feedlot were eligible for the study. These cattle came from 48 backgrounding operations located in six U.S. states (CO, IA, MO, ND, NE, and SD). Ten cattle cohorts (feedlot subpopulations), each with approximately 1700 cattle, were defined based on the dates at which they were sorted at the feedlot for a summer finishing period. Ninety-six cattle were randomly selected from each cohort for fecal sampling. Sample size estimates were determined for the intervention study (Cull et al., 2012).

Rectal fecal grab samples of approximately $30 \mathrm{~g}$ were collected from individual cattle using a rectal sleeve. After collection, samples were shipped on ice overnight to the Preharvest Food Safety Laboratory at Kansas State University for processing. Demographic data (source of origin, arrival date, days on feed [DOF], body weight upon arrival, allocation and sale dates) were collected with the purpose of describing the study population.

\section{Laboratory protocols for detection of STEC}

Approximately $1 \mathrm{~g}$ of each fecal sample was mixed in $9 \mathrm{~mL}$ of E. coli broth (EC; Oxoid Ltd., Hampshire, UK), and incubated at $40^{\circ} \mathrm{C}$ for $6 \mathrm{~h}$ (Paddock et al., 2012). A 1.0-mL sample of the enriched fecal suspension was placed in a $1.5-\mathrm{mL}$ microcentrifuge tube, boiled for $10 \mathrm{~min}$, and centrifuged at $10,000 \times g$ for $5 \mathrm{~min}$. DNA was extracted and purified with a GeneClean Turbo DNA extraction kit (MP Biomedicals, Solon, $\mathrm{OH}$ ) and tested by an 11-gene multiplex PCR assay that detects the seven serogroups (O26, O45, O103, O111, O121, O145, and O157) and four major virulence genes (stx1, st 2 , eae, and ehxA; Bai et al., 2012) (referred hereafter as "direct PCR"). A 1.0-mL sample of the enriched fecal suspension from the EC was also subjected to immunomagnetic separation (IMS) with Dynabeads ${ }^{\circledR}$ (Invitrogen, Carlsbad, CA) for O26, O103, and O111 serogroups. Fifty microliters of the O26, O103, and $\mathrm{O} 111$ bead suspensions were streaked on MacConkey (MAC) agar plates and incubated for $18-24 \mathrm{~h}$ at $37^{\circ} \mathrm{C}$. Then, 10 lactose-fermenting colonies, randomly picked from each sample, were mix together with $1 \mathrm{~mL} 0.1 \%$ peptone water. Fifty microliters of the colony mixture-peptone water suspensions from each sample were boiled for $10 \mathrm{~min}$ to then be subjected to the 11-gene multiplex PCR assay (Bai et al., 2012) to detect the seven O serogroups and four virulence genes (referred hereafter as "culture-based method").

\section{Statistical analyses}

Cumulative point prevalence estimates for each STEC serogroup and virulence gene were calculated at the sample level across all cohorts as the proportion of samples testing positive divided by the total number of samples tested $(n=960)$. Within-cohort prevalence for each serogroup and virulence gene was determined as the proportion of samples testing positive for each gene in each cohort divided by the total number of cattle tested within each cohort ( $n=96$ per cohort). Apparent cumulative and within-cohort prevalence were estimated for both detection methods.

To estimate cumulative mean prevalence at the cohort level, a random-effects model with a random intercept for cohort was used to adjust prevalence estimates for lack of independence associated with collecting multiple fecal samples from each cohort. Generalized linear mixed models used Laplace estimation, Newton-Raphson and Ridging optimization, a binomial distribution, and a logit link (Proc Glimmix SAS 9.3, SAS Institute Inc., Cary, NC). Outcome variables were modeled as binomial proportions as the number of positive samples (events)/number of samples tested per cohort (trials). An independent model was run for each STEC serogroup and detection method (culturebased and direct PCR). Prevalence estimates were calculated from model intercepts using the following formulae: $\mathrm{e}^{\beta 0} / 1+\mathrm{e}^{\beta 0}$ where $\beta^{0}$ is the coefficient of the model intercept. To estimate associations between cohort and prevalence of each STEC serogroup (within-cohort prevalence estimates), a categorical cohort variable was included as a fixed effect in regression models using a binomial distribution and logit link (with no random effects).

To assess overall agreement on the presence or absence of STEC serogroups in fecal samples between direct PCR and culture-based methods, the Cohen's $\kappa$ statistic and the McNemar's chi-square test were estimated (Dohoo et al., 2009). The degree of agreement was interpreted based on the scale proposed by Landis and Koch (1977).

\section{Results}

\section{Characteristics of the study population}

Cattle within each cohort were from a range of eight to 17 different backgrounding farms in three to five U.S. states. Overall mean cattle body weight was $393.7 \mathrm{~kg}$ (standard error of mean $[S E M]=0.4 \mathrm{~kg}$ ), with a median of $339.2 \mathrm{~kg}$, and range of $89.4-483.1 \mathrm{~kg}$. Within cohorts, mean body weight ranged from 365.8 to $419.8 \mathrm{~kg}$. At the start of the study, the mean DOF at the feedlot was 117 days (SEM=0.1 days; range $=37-237$ days), whereas the mean DOF by cohort ranged from 102 to 138 days.

\section{Prevalence of seven STEC O serogroups based on direct $P C R$}

Direct PCR identified serogroup O157 most frequently, with $48.2 \%$ (463/960) of samples testing positive (Table 1). Among non-O157 STEC serogroups, O26 (23.4\%), O121 $(16.4 \%)$, and $\mathrm{O} 103(11.8 \%)$ were the most prevalent serogroups detected by direct PCR followed by O45 (10.8\%), O145 (0.03\%), and O111 (0.01\%) (Table 1). Among samples positive for non-O157 $\mathrm{O}$ serogroups, a greater proportion $(p<0.01)$ tested positive for stx $2(69.0-100 \%)$ than for st $x 1$ (46.9-77.8\%). A similar pattern was observed for O157, where $69.3 \%(321 / 463)$ of samples tested positive for st $x 2$ compared to $56.8 \%(263 / 463)$ that tested positive for st $1(p<0.01)$. 
Table 1. Percentage of Fecal Samples (Total=960) Testing Positive for Shiga Toxin-Producing Escherichia COLI O Serogroup (O26, O45, O103, O111, O121, O145, and O157) and Virulence (stx1, stX2, eae, ehXA) Genes Using Direct Polymerase Chain Reaction (PCR) and O26, O103, and O111 Immunomagnetic Separation (IMS) Culture-Based Methods

\begin{tabular}{|c|c|c|c|c|}
\hline \multirow{2}{*}{$\begin{array}{l}\text { Serogroup specific- } \\
\text { and virulence genes }\end{array}$} & \multirow[b]{2}{*}{ Direct PCR \% (n) } & \multicolumn{3}{|c|}{ Culture-based } \\
\hline & & O26 IMS beads, \% (n) & O103 IMS beads, \% (n) & O111 IMS beads, \% (n) \\
\hline $\mathrm{O} 26$ & $23.4(225)$ & $30.5(293)$ & $13.4(129)$ & $12.1(116)$ \\
\hline $\mathrm{O} 45$ & $10.8(104)$ & $3.1(30)$ & $3.9(38)$ & $2.3(22)$ \\
\hline O103 & $11.8(113)$ & $5.5(53)$ & $29.7(285)$ & $26.0(250)$ \\
\hline O111 & $0.01(9)$ & $9.6(92)$ & $10.2(98)$ & $10.1(97)$ \\
\hline O121 & $16.4(157)$ & $1.9(18)$ & $2.2(21)$ & $1.7(16)$ \\
\hline O145 & $0.03(29)$ & $2.9(28)$ & $1.8(17)$ & $1.6(15)$ \\
\hline O157 & $48.2(463)$ & $6.0(58)$ & $4.3(41)$ & $4.1(39)$ \\
\hline$s t x 1$ & $44.4(426)$ & $20.1(193)$ & $12.2(117)$ & $10.6(102)$ \\
\hline stx 2 & $63.5(610)$ & $24.3(233)$ & $22.4(215)$ & $19.7(189)$ \\
\hline eae & $77.4(743)$ & $13.7(132)$ & $17.4(167)$ & $15.1(145)$ \\
\hline $\operatorname{eh} x A$ & $95.0(912)$ & $39.9(383)$ & $45.8(440)$ & $45.3(435)$ \\
\hline
\end{tabular}

Numbers in bold indicate percentage of O-serogroup-positive samples for the particular serogroup that the beads were designed to detect.

Approximately 33\% (315/960) of samples were positive for two or more STEC serogroups based on direct PCR. Conversely, 34.2\% (328/960) of samples were negative for all seven STEC serogroups. The distribution of serogroups and corresponding virulence markers is reported in Table 2. Estimates of apparent cumulative and within-cohort prevalence accounting for the hierarchical structure of the data (modeladjusted prevalence) are reported in Table 3 . The prevalence of $\mathrm{O}$ serogroups across cattle cohorts (and sampling time) did not indicate a readily apparent temporal pattern, but cohorts $3,4,7$, and 9 seemed to have numerically greater prevalence values (Table 3 and Fig. 1).

\section{Prevalence of O26, 0103, and 0111 serogroups based on culture-based assays}

A total of $30.5 \%(293 / 960)$ of samples tested positive for O26 by the culture-based method. Similarly, 29.7\% (285/960) and $10.1 \%(97 / 960)$ of samples were positive for O103 and O111, respectively (Table 1). Samples positive for O26 tested positive for stx $1(45.4 \%, 133 / 293)$ and stx $2(35.8 \%, 105 / 293)$. A greater number of $\mathrm{O} 103$ and $\mathrm{O} 111$ positive samples tested positive for $s t x 2(39.3 \%$ and $36.1 \%, p<0.01$, respectively) than for the $s t x 1$ gene $(23.8 \%$ and $23.7 \%$, respectively). Detection of other STEC serogroups and the distribution of virulence determinants are reported in Tables 1 and 2 . Overall model-adjusted cumulative and within-cohort prevalence estimates of STEC O serogroups are reported in Table 3.

\section{Comparisons between direct PCR and culture-based detection protocols}

More O26, O103, and O111 positive samples were detected by culture-based methods $(p<0.01)$ than by direct PCR; however, the detection of virulence genes after culture was considerably lower $(p<0.01)$ than the proportion testing positive by direct PCR.

McNemar's chi-square test statistics for all comparisons of the proportions of positive samples identified by direct

Table 2. Distribution of Virulence Genes in Bovine Fecal Samples Positive for O-Specific Serogroup Genes by Direct Polymerase Chain Reaction (PCR) and O26, O103, and O111 Immunomagnetic Separation (IMS) Culture-Based Methods

\begin{tabular}{|c|c|c|c|c|c|c|c|c|}
\hline $\begin{array}{l}\text { Detection } \\
\text { method and } \\
\text { serogroups }\end{array}$ & $\begin{array}{c}\text { Positive } \\
\text { O-serogroup } \mathrm{n}\end{array}$ & $\begin{array}{c}\text { stx1 (+) and } \\
\text { stx2 (+) } \\
\%(\mathrm{n})\end{array}$ & $\begin{array}{c}\text { stx1 (+) and/or } \\
\text { stx2 (+) } \\
\%(\mathrm{n})\end{array}$ & $\begin{array}{c}\text { stx1 (-) and } \\
\text { stx2 (-) } \\
\%(\mathrm{n})\end{array}$ & $\begin{array}{c}\text { eae (+) } \\
\%(\mathrm{n})\end{array}$ & $\begin{array}{c}\text { stx1 and/or } \\
\text { stx2, eae (+) } \\
\%(n)\end{array}$ & $\begin{array}{c}\text { stx1 }(-), \text { stx2 } \\
(-), \text { eae }(+) \\
\%(n)\end{array}$ & $\begin{array}{c}\text { stx1 }(-), \text { stx2 } \\
(-), \text { eae }(-) \\
\%(\mathrm{n})\end{array}$ \\
\hline \multicolumn{9}{|l|}{ Direct PCR } \\
\hline $\mathrm{O} 26$ & 225 & $55.6(125)$ & $80.0(180)$ & $20.0(45)$ & 86.2 (194) & $72.0(162)$ & 14.2 (32) & 5.8 (13) \\
\hline $\mathrm{O} 45$ & 104 & $48.1(50)$ & 87.5 (104) & $12.5(13)$ & 84.6 (88) & 73.1 (76) & $11.5(12)$ & 1.0 (1) \\
\hline O103 & 113 & $41.6(47)$ & $83.2(94)$ & 16.8 (19) & $88.5(100)$ & $73.4(83)$ & 15.0 (17) & $1.8(2)$ \\
\hline O111 & 9 & $77.8(7)$ & $100.0(9)$ & $0.0(0)$ & $100.0(9)$ & $100.0(9)$ & $0.0(0)$ & $0.0(0)$ \\
\hline O121 & 157 & $67.5(106)$ & 87.3 (137) & $12.7(20)$ & $92.4(145)$ & $82.8(130)$ & $9.6(15)$ & $3.2(5)$ \\
\hline O145 & 29 & $41.4(12)$ & $79.3(23)$ & $20.7(6)$ & $96.6(28)$ & $75.9(22)$ & $20.7(6)$ & $0(0)$ \\
\hline O157 & 463 & 49.9 (231) & 76.2 (353) & $23.8(110)$ & 84.4 (391) & $70.4(326)$ & 23.7 (110) & 9.7 (45) \\
\hline \multicolumn{9}{|l|}{ Culture-based } \\
\hline O26-IMS & 293 & $16.7(49)$ & 64.5 (189) & 35.5 (104) & $16.4(48)$ & 11.9 (35) & $4.4(13)$ & 31.1 (91) \\
\hline O103-IMS & 285 & $12.3(35)$ & 50.9 (145) & 49.1 (140) & 35.8 (102) & 20.7 (59) & $15.1(43)$ & 34.0 (97) \\
\hline O111-IMS & 97 & $8.2(8)$ & $51.5(50)$ & $48.4(47)$ & $44.3(43)$ & 23.7 (23) & $20.6(20)$ & 27.8 (27) \\
\hline
\end{tabular}




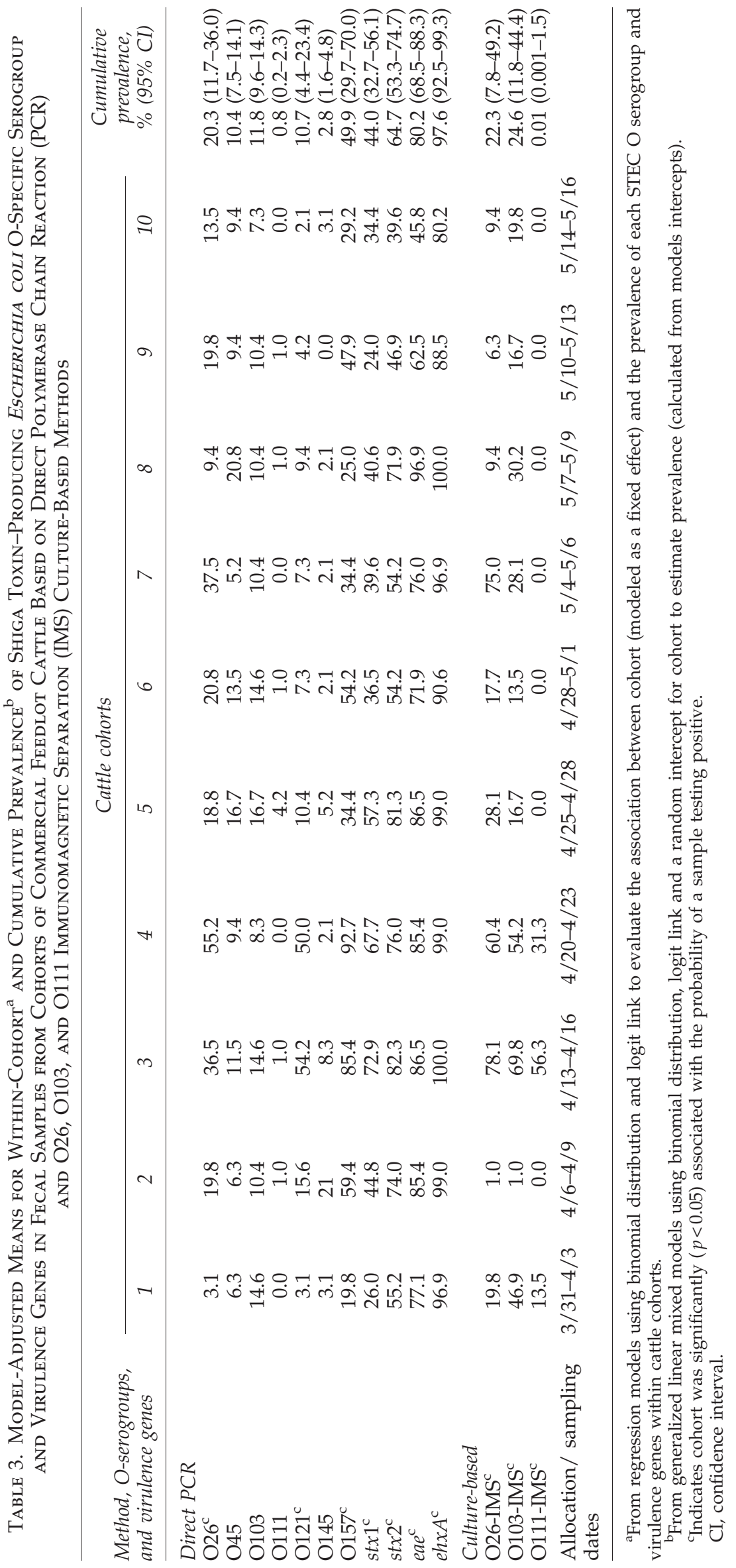




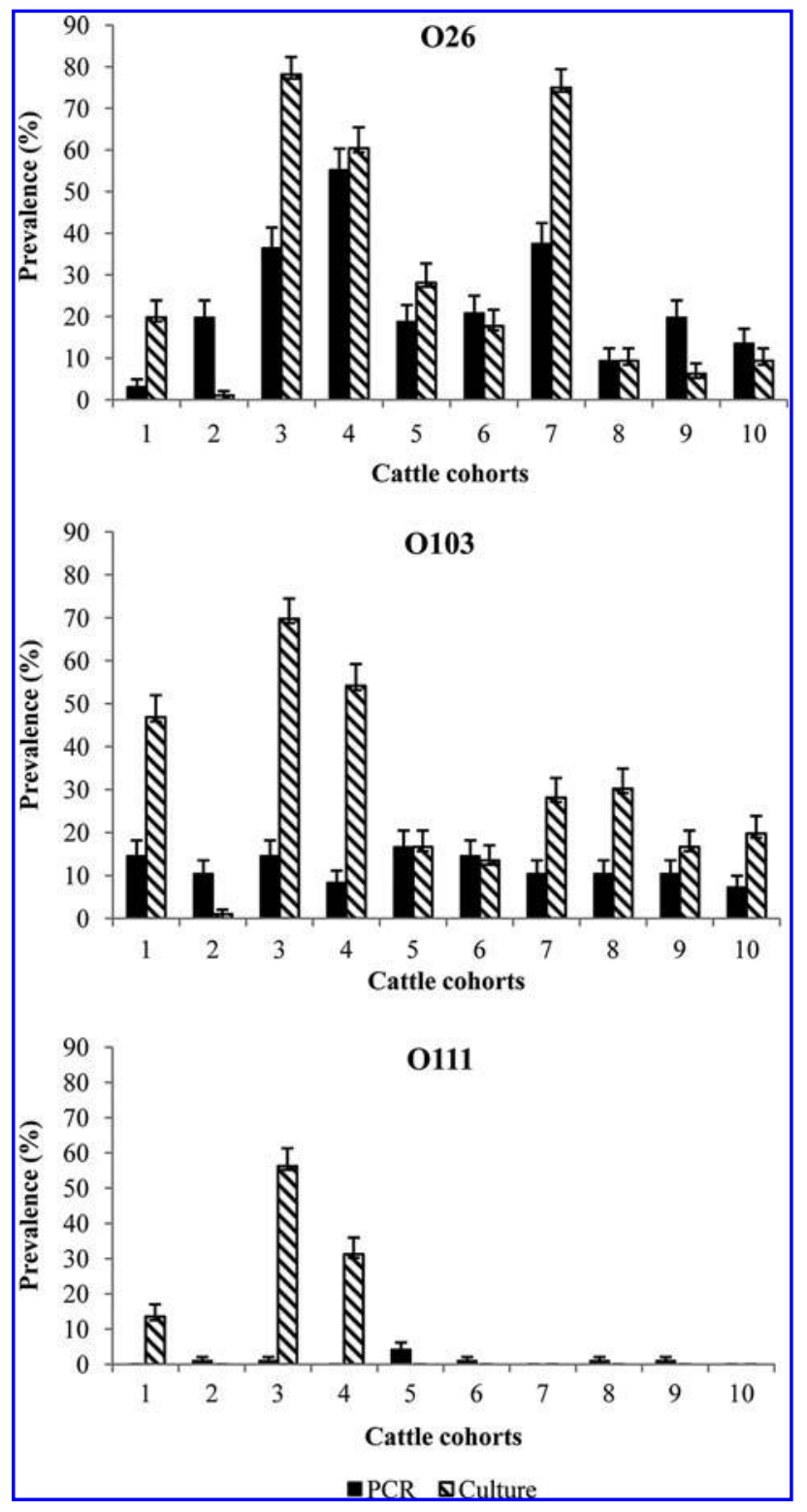

FIG. 1. Model-adjusted means (from regression models using a binomial distribution and logit link to evaluate the association between cohort [modeled as a fixed effect] and the prevalence of each Shiga toxin-producing Escherichia coli [STEC] O serogroup within cattle cohorts) for within-cohort prevalence of STEC O26, O103, and O111 serogroups in feedlot cattle feces based on direct polymerase chain reaction and culture-based detection methods. Error bars indicate standard errors of model-adjusted means.

PCR and culture-based procedures indicated disagreement $(p<0.01)$. Therefore, the following Cohen's $\kappa$ statistics should be considered biased and used for reference only. Kappa results indicated there was a significant $(p<0.01)$, albeit only fair, degree of agreement between direct PCR and culture-based results for detection of O26 (agreement $=71.9 \%, \quad \kappa=29.1 \%$ ) and O103 (agreement $=72.9 \%$, $\kappa=21.4 \%$ ) serogroups. The overall agreement between the two tests for detection of O111 STEC beyond that due to chance was slight $(\kappa=0.2 \%)$, and not statistically significant $(p=0.46)$.

\section{Discussion}

The fecal prevalence of STEC serogroups of potential public health importance was determined in commercial feedlot cattle cohorts using PCR and cultural methods. Recent increases in the number and clinical relevance of cases attributed to non-O157 STEC in North America and Europe dictate that research into the prevalence of STEC in cattle should be conducted to generate data for quantitative risk assessments (Brooks et al., 2005; Pihkala et al., 2012; Scallan et al., 2011). The few published on-farm studies of non-O157 STEC in the United States report point-estimates of prevalence. There are challenges related to the use of point-prevalence measures to describe the epidemiology of enteric pathogens, including the phenomena of intermittent shedding, possible re-infections, and changes over time, particularly due to seasonal shedding (Barkocy-Gallagher et al., 2003; Renter et al., 2005). Variable accuracy of diagnostic tests for STEC also impact prevalence estimates. Longitudinal studies are impacted by similar factors, yet they are more appropriate for evaluating outcomes that vary over time. However, there are limited longitudinal investigations of non-O157 STEC epidemiology on beef farms. The current study was motivated by the need to acquire information on the prevalence of STEC organisms shed by feedlot cattle populations into the production environment.

Based on PCR and cultural methods, our cumulative prevalence estimates ranged from 0.01 to $24.6 \%$ for STEC serogroups, whereas our within-cohort prevalence estimates varied widely ( 0 to $78.1 \%$ ). Although our estimates are within previously reported fecal prevalence estimates (Jenkins et al., 2003; Renter et al., 2005; Hussein, 2007), the diagnostic methods differed in these studies and thus prevalence estimates are difficult to compare. Our apparent prevalence estimates are based on two diagnostic protocols; however, estimates of true STEC prevalence are still lacking. Although samples were obtained from a single commercial feedlot, sampled cohorts were representative of a large population of cattle originating from several backgrounding farms across six states. Elucidating and controlling factors that reduce the prevalence of STEC, regardless of whether they relate to incidence, duration of shedding, or a combination of both, could have public health benefits by limiting potential foodborne and environmental exposures.

For detection of non-O157 STEC in trim or other groundbeef components, the FSIS (2010) proposed a two-stage PCR screening test on post-enrichment samples, followed by IMS and inoculation onto Rainbow agar, with confirmation by latex agglutination and biochemical tests. However, currently there are no specific tests or protocols standardized for use in more complex matrices, such as feces. We selected a random sample of colonies from MacConkey agar, a medium selective for E. coli but relatively nondifferential, to detect target serogroups by multiplex PCR in order to increase unbiased detection capabilities. For culture-based procedures, we used three sets of beads intended to separate O26, O103, and O111. Although both O26 and O103 IMS beads appear to be relatively specific for the respective serogroups, colonies from O111 beads were often positive for the O103 gene (Table 1). This supports previous findings reported by Bai et al. (2012). The detection of other STEC serogroups is likely due to nonspecific binding on the beads and subsequent use of a nondifferential medium. 
Isolation of STEC obtained by culture-based methods followed by PCR confirmation of serogroup and virulence genes, or the detection of gene markers using PCR directly on enriched samples, was shown to be advantageous for testing fecal samples that may harbor more than one serogroup and may not possess Shiga toxin or intimin genes (Bai et al., 2012; Paddock et al., 2012). Other fecal prevalence studies (Cobbold et al., 2004; Renter et al., 2007) followed an FSIS-type approach (FSIS, 2010) by prescreening samples for Shiga toxin genes before applying cultural methods. Use of PCR as a prescreening tool for feces may be suboptimal as it can fail to detect O-positive samples that, despite their pathogenic potential, do not contain virulence genes; conversely, it can amplify virulence genes that are carried by other bacteria. Among samples positive for $\mathrm{O}$ genes, the presence of virulence genes varied considerably. A large number of samples positive for $\mathrm{O}$ serogroups, by both culture-based and direct PCR methods, did not possess either Shiga toxin gene, indicating that cattle carry Shiga toxin gene-negative E. coli belonging to these seven $\mathrm{O}$ serogroups. This phenomenon has been previously observed with $\mathrm{O} 157$ (Bielaszewska et al., 2007; Wetzel and LeJeune, 2007; Cernicchiaro et al., 2009), and non-O157 STEC strains in cattle feces (Bai et al., 2012; Paddock et al., 2012).

The presence of multiple STEC serogroups in cattle feces may be relatively common, as $14-16 \%$ of samples tested positive for two or more $\mathrm{O}$ serogroups based on culture-based protocols, and $33 \%$ based on direct PCR. Simultaneous detection of serogroup and virulence genes by the multiplex PCR does not indicate that virulence determinants are carried by the same serogroup. This issue should be further investigated in order to characterize STEC risk associated with cattle production systems. Paddock et al. (2012) and Bai et al. (2012) concluded that multiplex PCR for STEC serogroups is most applicable for confirming putative isolates. Our results support their findings that culture-based methods using specific IMS beads followed by PCR confirmation of serogroup and virulence genes identifies a greater number of O-positive samples than using PCR directly. However, the significant disagreement between PCR and culture-based protocols indicates that further assessments are necessary. There is a need to determine the diagnostic sensitivity and specificity of STEC detection procedures, and further evaluate potential impacts of cross-reactivity, use of a nonselective medium, and fecal inhibitors of PCR amplification.

Detection of virulence markers after cultural isolation was low compared to direct PCR. It may be that PCR detected genes carried by bacteria other than the targeted STEC serogroups. Methods for isolation and detection of non-O157 STEC in feces are still under development (Possé et al., 2008; Bai et al., 2012; Hedge et al., 2012; Paddock et al., 2012; Wylie et al., 2013); specific potential needs are to develop a selective medium to phenotypically identify STEC serogroups, improve specificity of IMS beads, validate molecular techniques for faster and more sensitive detection, and standardize protocols to accurately identify STEC.

Associations between cohort and the probability of detecting serogroups O26, O103, O111, and O157 indicates that prevalence significantly varied among cattle subpopulations or sampling time. Seasonal effects have been identified for E. coli O157:H7 (Chapman et al., 1997; Barkocy-Gallagher et al., 2003; Smith et al., 2005; Edrington et al., 2006; Williams et al.,
2010), with the occurrence being greatest in summer months. A previous study indicated that the fecal prevalence of nonO157 STEC also could vary seasonally; however, there were no clear trends, perhaps due to the low recovery rate of STEC (Barkocy-Gallagher et al., 2003). Renter et al. (2005) showed the probability of detecting non-O157 STEC varied over time, but no seasonal pattern was observed. Given that sample collection in this current study was during a 2-month frame within the same season, and sampling time was confounded by cohort, the effect of season could not be evaluated.

Results indicate that all seven STEC O serogroups and associated virulence determinants were detected, at various levels, in fecal samples from commercial cattle cohorts. The O157, O26, and O103 serogroups were the most frequently detected in this study population. Multiple serogroup-positive samples did not harbor Shiga toxin genes; thus, further elucidation of their role as potential human pathogens is important. Evaluation of diagnostic methods for non-O157 STEC is needed, given their fairly poor agreement and impact on prevalence estimation. Prospect advancement in the development and validation of diagnostic techniques for STEC, generation of longitudinal epidemiologic data, and identification of factors associated with the presence and persistence of STEC are also needed. These efforts will improve true prevalence estimates that provide measures of pathogen frequency at the feedlot level and contribute data to assessments aimed at identifying potential risks of human illness related to beef production.

\section{Acknowledgments}

The authors wish to thank Neil Wallace for his assistance in the laboratory. Research was supported by the Agriculture and Food Research Initiative Competitive Grants no. 200835201-04679 and 2012-68003-30155 from the USDA National Institute of Food and Agriculture, and the College of Veterinary Medicine, Kansas State University. This article is contribution number 13-166-J from the Kansas Agricultural Experiment Station.

\section{Disclosure Statement}

No competing financial interests exist.

\section{References}

Bai J, Paddock ZD, Shi X, Li S, An B, Nagaraja TG. Applicability of a multiplex PCR to detect the seven major Shiga toxinproducing Escherichia coli based on genes that code for serogroup-specific $\mathrm{O}$-antigens and major virulence factors in cattle feces. Foodborne Pathog Dis 2012;9:541-548.

Barkocy-Gallagher GA, Arthur TM, Rivera-Betancourt M, Nou X, Shackelford SD, Wheeler T L, Koohmaraie M. Seasonal prevalence of Shiga toxin-producing Escherichia coli, including O157:H7 and non-O157:H7 serotypes, and Salmonella in commercial beef processing plants. I Food Prot 2003;66:19781986.

Bettelheim KA. Role of non-O157 VTEC. J Appl Microbiol 2000;88:38S-50S.

Bielaszewska M, Kock R, Friedrich AW, Zimmerhachl LB, Karch $\mathrm{H}$, Mellmann A. Shiga toxin-mediated hemolytic uremic syndrome: Time to change the diagnostic paradigm. PloS ONE 2007;2910:e1024. 
Bosilevac JM, Guerine MN, Brichta-Harhay DM, Arthur TM, Koohmaraie M. Microbiological characterization of imported and domestic boneless beef trim used for ground beef. $\underline{\mathrm{J} \text { Food }}$ Prot 2007;70:440-449.

Bosilevac JM, Koohmaraie M. Prevalence and characterization of non-O157 Shiga toxin-producing Escherichia coli isolates from commercial ground beef in the United States. Appl Environ Microbiol 2011;77:2103-2112.

Brooks JT, Sowers EG, Wells JG, Greene KD, Griffin PM, Hoekstra RM, Strockbine NA. Non-O157 Shiga toxin-producing Escherichia coli infections in the United States, 1983-2002. I Infect Dis 2005;192:1422-1429.

Cernicchiaro N, Pearl DL, Ghimire S, Gyles CL, Johnson RP, LeJeune JT, Ziebell K, McEwen SA. Risk factors associated with Escherichia coli O157:H7 in Ontario beef cow-calf operations. Prev Vet Med 2009;92:106-115.

Chapman PA, Siddons CA, Cerdan Malo AT, Harkin MAA. 1year study of Escherichia coli O157 in cattle, sheep, pigs and poultry. Epidemiol Infect 1997;119:245-250.

Cobbold RN, Rice DH, Szymanski M, Call DR, Hancock DD. Comparison of Shiga-toxigenic Escherichia coli prevalences among dairy, feedlot, and cow-calf herds in Washington State. Appl Environ Microbiol 2004;70:4375-4378.

Cull CA, Paddock ZD, Nagaraja TG, Bello NM, Babcock AH, Renter DG. Efficacy of a vaccine and a direct-fed microbial against fecal shedding of Escherichia coli O157:H7 in a randomized pen-level field trial of commercial feedlot cattle. Vaccine 2012;30:6210-6215.

Dohoo I, Martin W, Stryhn H. Screening and diagnostic tests. In: Veterinary Epidemiologic Research, 2nd ed. Charlottetown, Prince Edward Island: AVC Inc., 2009, pp. 91-134.

Edrington TS, Callaway TR, Ives S, Engler MJ, Looper ML, Anderson RC, Nisbet J. Seasonal shedding of Escherichia coli O157:H7 in ruminants: A new hypothesis. Foodborne Pathog Dis 2006;3:413-421.

[FSIS] Food Safety and Inspection Service, FSIS-USDA, 2010. MLG 5B.00, FSIS Microbiology Laboratory Guidebook. Available at: http://www.fsis.usda.gov/PDF/Mlg_5B_00.pdf, accessed March 1, 2013.

Fratamico PM, Bagi LK, Cray WC, Narang N, Yan X, Medina M, Liu Y. Detection by multiplex real time polymerase chain reaction assays and isolation of Shiga toxin-producing Escherichia coli serogroups O26, O145, O103, O111, O121, and O145 in ground beef. Foodborne Pathog Dis 2011;8:601-607.

Hedge NV, Cote R, Jayarao BM, Muldoon M, Lindpaintner K, Kapur V, DebRoy C. Detection of the top six non-O157 Shiga toxin-producing Escherichia coli $\mathrm{O}$ groups by ELISA. Foodborne Pathog Dis 2012;9:1044-1048.

Hofer E, Stephan R, Reist M, Zweifel C. Application of real-time PCR-based system for monitoring of O26, O103, O111, O145, and O157 Shiga toxin-producing Escherichia coli in cattle at slaughter. Zoonoses Public Health 2012;59:408-415.

Hussein HS. Prevalence and pathogenicity of Shiga toxin-producing Escherichia coli in beef cattle and their products. $\underline{\text { Anim }}$ Sci 2007;85:E63-E72.

Jenkins C, Pearce MC, Smith AW, Knight HI, Shaw DJ, Cheasty T, Foster G, Gunn GJ, Dougan G, Smith HR, Frankel G. Detection of Escherichia coli serogroups O26, O103, O111 and O145 from bovine feces using immunomagnetic separation and PCR/DNA probe techniques. Lett Appl Microbiol 2003;37:207-212.

Landis JR, Koch GG. The measurement of observer agreement for categorical data. Biometrics 1977;33:159-174.
Paddock Z, Shi X, Bai J, Nagaraja TG. Applicability of a multiplex PCR to detect O26, O45, O103, O111, O121, O145, and O157 serogroups of Escherichia coli in cattle feces. Vet Microbiol 2012;156:381-388.

Painter JA, Hoekstra RM, Ayers T, Tauxe RV, Braden CR, Angula FJ, Griffin PM. Attribution of foodborne illnesses, hospitalizations, and deaths to food commodities by using outbreak data, United States, 1998-2008. Emerg Infect Dis 2013;19:407-415.

Pihkala N, Bauer N, Eblen D, Evans D, Johnson R, Webb J, Williams C. Risk profile for pathogenic non-O157 Shiga toxinproducing Escherichia coli (non-O157 STEC). Office of Public Health Science, Office of Policy and Program Development, USDA-FSIS. May 2012. Available at: http://www.fsis.usda.gov/ .PDF/Non_O157_STEC_Risk_Profile_May2012.pdf, accessed March 1, 2013.

Possé B, De Zutter L, Heyndrickx M, Herman L. Novel differential and confirmation plating media for Shiga toxinproducing Escherichia coli serotypes O26, O103, O111, O145 and sorbitol-positive and negative O157. FEMS Microbiol Lett 2008;282:124-131.

Renter DG, Morris JG Jr, Sargeant JM, Hungerford LL, Berezowski J, Ngo T, Williams K, Acheson DW. Prevalence, risk factors, O serogroups, and virulence profiles of Shiga toxinproducing bacteria from cattle production environments. J Food Prot 2005;68:1556-1565.

Renter DG, Bohaychuk V, Van Donkersgoed J, King R. Presence of non-O157 Shiga toxin-producing Escherichia coli in feces from feedlot cattle in Alberta and absence on corresponding beef carcasses. Can J Vet Res 2007;71:230-235.

Scallan E, Hoekstra RM, Angulo FJ, Tauxe RV, Widdowson MA, Roy SL, Jones JL, Griffin PM. Foodborne illness acquired in the United States-major pathogens. Emerg Infect Dis 2011;17:7-15.

Smith DR, Moxley RA, Clowser SL, Folmer JD, Hinkley S, Erickson GE, Klopfenstein TJ. Use of rope devices to describe and explain the feedlot ecology of Escherichia coli O157:H7 by time and place. Foodborne Pathog Dis 2005;2:50-60.

Wetzel AN, LeJeune JT. Isolation of Escherichia coli O157:H7 strains that do not produce Shiga toxin from bovine, avian and environmental sources. Lett Appl Microbiol 2007;45:504507.

Williams MS, Withee JL, Ebel ED, Bauer NE Jr, Scholsser WD, Disney WT, Smith DR, Moxley RA. Determining relationships between the seasonal occurrence of Escherichia coli O157:H7 in live cattle, ground beef and humans. Foodborne Pathog Dis 2010;7:1247-1254.

Wylie JL, Van Caeseele P, Gilmour MW, Sitter D, Guttek C, Giercke S. Evaluation of a new chromogenic agar medium for detection of Shiga toxin-producing Escherichia coli (STEC) and relative prevalence of $\mathrm{O} 157$ and non-O157 STEC, Manitoba, Canada. J Clin Microbiol 2013;51:466-471.

Address correspondence to: David G. Renter, DVM, PhD Department of Diagnostic Medicine and Pathobiology College of Veterinary Medicine \#307 Coles Hall Kansas State University Manhattan, KS 66506

E-mail: drenter@ksu.edu 